\section{Contributors}

Dan Edgcumbe is a GP registrar in Histon, Cambridgeshire. A vote on Revalidation? Edgy, My Boy!! dr.edgcumbe@gmail.com

Ian McKelvey is a GP Trainer and Appraiser at the Petroc Group Practice in Cornwall.

lan.McKelvey@Petrocdocs.cornwall. NHS.UK

\section{Lesley Morrison}

lesley@ljmorrison.fsnet.co.uk

\section{Nigel de Kare-Silver}

Nigel.DeKARE-SILVER

@londondeanery.ac.uk

\section{Mike Fitzpatrick}

fitz@easynet.co.uk

Simon Fraser has been a GP Principa in a busy urban practice in Southampton for several years. He stuck his head above the parapet 3 years ago and decided to go and train in Public Health part time (while continuing as a GP). The heady view from this new perspective has generated some interesting insights on both sides of the fence. simon.fraser@nhs.net

Adrian Lamb is a GP working in an urban practice, Leeds. His CV includes working as a Doctor for an island aboriginal reserve in Australia, a Homeless and Assylum Seeker Health Centre in Inner City Bradford, and Prison Services in Yorkshire. He is part of a Doctors' 'Reflective Writing' group which meets to read out, and hear personal pieces of prose or poetry. adrian.lamb@nhs.net

Samir Dawlatly is an ST2 GP trainee in the West Midlands, undertaking his GP training on the South Birmingham Vocational Scheme. He is a graduate for the University of Birmingham Medical School, where he spent 9 years collecting an $\mathrm{MBChB}, \mathrm{PhD}$ and BMedSc. He has recently completed a distance learning PGCME from the University of Dundee. samir.dawlatly@googlemail.com

\section{Saul Miller}

saulmiller@me.com

Robert Green should have been a part-time GP in the North East of London. Unfortunately he is a part-time England goalkeeper who keeps goal in the Scottish style. The word Mince springs to mind.

David Watson is in Edinburgh at present at the Film Festival. His review, next month, is eagerly awaited. I get to see the unexpurgated version, Yippee!

\title{
Keeping to target
}

'Thanks for coming back in,' I say as he enters.

'No problem, doc,' he replies casually, moving easily into the rotomolded plastic chair beside my oak desk.

'It's just that, now you have been in and had your blood pressure done by the nurse, a medicines review done by our dispenser, and your blood taken by our phlebotomist, I needed you back in to discuss results.' I look earnestly into his face.

'Oh,' he says with a mild look of surprise, 'I thought you might be wanting to check up on my asthma today, what with my wheezing and ...'

'No, no,' I butt in, smiling kindly. 'That will have to wait until you get the invitation letter to our asthma clinic next month. I hope it is not too much of an inconvenience coming in yet again today though?

'Not really,' he reassures me. 'I'm selfemployed and lost another contract but my health is more important than shoes on my children's feet.'

'Bravo!' I reply in encouragement, having momentarily switched off while consulting the computer screen before me. There is a silence as I look hard at the records before turning back to him.

$\mathrm{He}$ is waiting, concern writ large upon his brow. A picture of anticipation. I hesitate, adeptly amplifying this. Then I begin.

'I wanted to tell you about your chronic kidney disease.' I say, breaking into the topic gently.

'Oh,' he splutters through an embarrassed grin, 'I thought you were about to say cancer!'

Picking up on this cue instantly, I lean forwards with empathy. 'No,' I breathe, 'it is only diseased kidneys.'

'Phew!' he responds, wiping his brow in mock relief. 'Thought I was eating a bit much cabbage ...'

'Well, yes, you could perhaps cut down on that anyway,' I advise, tuning in to his illness framework.

I turn back to the computer again and silence falls once more. I click some keys; there is a pause. I glance over his shoulder at the clock. Cripes! 6 minutes gone already! Where does the time go?

The printer whirrs into life. I collect the 8 pages it churns out, select a urineyellow paper-clip, and hand it all over.

'What's this?' he asks, his tone confirming this to be a question asked against a background of genuine trust in my good intentions as a doctor.

'It's a printout,' I reply with warmth. 'It confirms your autonomy. It will tell you everything you need to know about your risk of progression and of an early death. That and some condescending reassurance about things you might do to improve your chances.'

'Like what?' he asks, flipping the pages, fazed by the amount of information on offer.

'Oh, like eating five kumquats a day, avoiding overhanging cliffs, and lifting your feet 3 inches off the ground every 5 minutes while watching TV in the evenings.'

'What does that do?' he asks innocently.

'Over the course of a year,' I answer, aware that over 8 minutes have now gone and I have not even started hunt-andpecking any of this yet, 'it adds up to the equivalent of climbing Everest ...'

'Wow!' he exclaims, clearly motivated by this.

'... twice,' I finish, 'depending on how much TV you watch of course.'

'Thanks doc,' he enthuses, folding his pages of information as though content with what has passed between us. $\mathrm{He}$ looks directly at me now. 'Is this a good time to mention my chronic penile thrush?'

'No,' I say, shaking my head firmly in a schoolmaster-ish way. 'Time's up!'

'Fair enough,' he says, standing and smiling his thankfulness. 'I'll ask for another appointment on my way out.'

'It won't be with me of course,' I point out, 'but you'll find us all excellent.'

'Quite,' he agrees, opening the door and looking back. 'Your notes are so thorough, I find any doc'll do.'

The door closes. Twelve seconds to record the consultation.

DOI: 10.3399/bjgp10X515007 